\title{
Orientação teórica e os cenários de prática na formação de terapeutas ocupacionais na atenção primária à saúde: perspectivas de docentes ${ }^{1}$
}

\author{
Rodrigo Alves dos Santos Silva ${ }^{a}$, Fátima Corrêa Oliver ${ }^{\mathrm{a}, \mathrm{b}}$ \\ aUniversidade Federal de São Carlos - UFSCar, São Carlos, SP, Brasil.

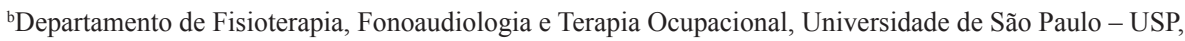 \\ São Paulo, SP, Brasil.
}

\begin{abstract}
Resumo: Objetivo: O objetivo deste artigo é descrever e analisar a orientação teórica e os cenários de prática na formação de terapeutas ocupacionais na Atenção Primária à Saúde (APS). Método: Trata-se de uma pesquisa qualitativa, que apresenta as perspectivas de 17 docentes de nove cursos de terapia ocupacional do Estado de São Paulo. Resultados: Foi realizada categorização de temas associados ao objetivo do estudo e, para este artigo, apresentamos duas categorias: Orientação teórica - que compreende o estudo do referencial de Alma Ata (1978); da Reforma Sanitária; da compreensão crítica do Sistema Único de Saúde, da APS e da especificidade da profissão nesse campo, que envolve o entendimento dos dispositivos que contemplam o terapeuta ocupacional nas equipes e de suas ferramentas de trabalho, e a compreensão sobre vulnerabilidade social, vida cotidiana e contexto institucional, que envolve os serviços e sua gestão. Já em relação aos Cenários de Prática foi identificada uma pluralidade de serviços e desenhos de gestão, nos quais se desenvolvem as atividades teórico-práticas, o que apontou uma dificuldade para realizar a formação para esse campo profissional. Além disso, a ausência de trabalhadores na APS dificulta o cuidado em saúde e também prejudica a formação de estudantes de diferentes áreas profissionais. Conclusão: Cabe também à categoria profissional valorizar, desde a formação graduada, o aprendizado de tecnologias de cuidado compatíveis com os seus saberes e recursos terapêutico-ocupacionais em direção ao acesso da população a diferentes práticas para o cuidado integral à saúde, incluindo-se o cuidado da terapia ocupacional na APS
\end{abstract}

Palavras-chave: Terapia Ocupacional, Formação de Profissionais de Saúde, Trabalho em Saúde, Atenção Primária à Saúde.

\section{Theoretical orientation and practice scenarios on occupational therapists training in primary health care: professors perspectives}

\begin{abstract}
Objective: This article aimed to describe and analyze the theoretical guidance and practical scenarios in the training of occupational therapists in Primary Health Care (PHC). Method: This is a qualitative research, which presents the perspectives of 17 teachers from nine occupational therapy courses in the state of São Paulo. Results: We categorized subjects associated to the study objective and present two categories: theoretical orientation - which includes the study of the referential Alma Ata (1978); Health Reform; critical understanding of the Unified Health System, the PHC and the profession specificity in this field involving understanding of the devices used by the teams occupational therapist and their working tools, social vulnerability understanding, everyday life and institutional context involving services and their management. The Practice Scenarios has been identified a plurality of services and drawings management where theoretical activities practices are developed, pointed out the difficulty of conducting training for this professional field. Moreover, the absence of workers on PHC hinders health care and also impairs
\end{abstract}

Autor para correspondência: Rodrigo Alves dos Santos Silva, Laboratório METUIA, Departamento de Terapia Ocupacional, Universidade Federal de São Carlos, Rodovia Washington Luiz, Km 235, CEP 13565-905, São Carlos, SP, Brasil, e-mail: rodrigosilva.to@gmail.com Recebido em Mar. 16, 2016; $1^{\text {a }}$ Revisão em Abr. 25, 2016; Aceito em Maio 9, 2016. 
the students training from different professional areas. Conclusion: The professional category must value since training, the learning of new care technologies compatible with their knowledge and occupational therapeutic resources towards the population's access to different practices for comprehensive health care, including the care of occupational therapy in PHC.

Keywords: Occupational Therapy, Training of Health Professionals, Work in Health, Primary Health Care.

\section{Introdução}

Estudos internacionais sobre a terapia ocupacional na Atenção Primária em Saúde (APS) abordam tanto a falta de financiamento, formação e limitada compreensão do papel da terapia ocupacional na APS (WOOD; FORTUNE; MCKINSTRY, 2013) como identificam poucas pesquisas que investigaram o papel do profissional nesse âmbito assistencial (DONNELLY et al., 2014). Além disso, mesmo que a profissão ainda não seja fortemente difundida nesse nível assistencial, a APS é vista como uma oportunidade para a terapia ocupacional, visto a sua contribuição aos cuidados da população, numa perspectiva holística (MUIR, 2012).

No Brasil, mesmo que a formação e as práticas de terapeutas ocupacionais tenham se dado em contextos territoriais e comunitários desde o final dos anos 1970 e nos anos 1980 e 1990, com experiências em Unidades Básicas de Saúde (ROCHA; SOUZA, 2011; BARROS; LOPES; GALHEIGO, 2007), é nos anos 2000, que vimos emergir mais reflexóes sobre a atuação do terapeuta ocupacional na APS, como apresentado pelo estudo bibliográfico realizado por Bassi, Malfitano e Bianchi (2012). As autoras buscaram conhecer a discussão sobre a formação e a intervenção na APS registrada pela terapia ocupacional, encontraram 21 artigos completos em revistas científicas específicas da área no país e identificaram uma tendência crescente de discussão sobre essa temática nos periódicos, o que também refletiria uma preocupação presente entre profissionais da APS.

Nesse contexto, identificamos modificaçóes na formação graduada, que passa por mudanças desde a Resoluçáo no 4, em 12/jan./1983, a qual, ao instituir o novo Currículo Mínimo para os cursos de terapia ocupacional do país, orientava uma formação para a prática profissional nos três níveis de atenção à saúde, já com aproximaçôes entre a terapia ocupacional e a APS (BASSI, 2012; SOARES, 1991). Na década de 1990, acontecem as discussões sobre legislações em torno da formação e da avaliação da educação superior brasileira. Essas discussões são decorrentes, principalmente, da Lei de Diretrizes e Bases da Educação Nacional LDBEN (BRASIL, 1996b), que acabou com os Currículos Mínimos para os cursos de nível superior no Brasil e instituiu a flexibilização curricular.

Dessa forma, após discussões do âmbito da formação de diferentes profissóes que atuam no setor saúde e da LDBEN, a graduação de terapeutas ocupacionais ficou regulamentada pelas Diretrizes Curriculares Nacionais do Curso de Graduação em Terapia Ocupacional, estabelecidas pelo Conselho Nacional de Educação (CNE), em 2002, com a publicação da Resolução no 6 (BRASIL, 2002). Essas Diretrizes, no seu Art. $3^{\circ}$, retrata o

Perfil do formando egresso/profissional, o terapeuta ocupacional, com formação generalista, humanista, crítica e reflexiva. Capacitado ao exercício profissional em todas as suas dimensões, pautado em princípios éticos, no campo clínico-terapêutico e preventivo das práticas de Terapia Ocupacional (BRASIL, 2002, p. 1).

As diretrizes curriculares de 2002 vêm norteando revisōes e adequaçôes nos Projetos Políticos Pedagógicos dos cursos de terapia ocupacional, o que vem implicando, de maneira recente, em mudanças para a formação dos futuros profissionais (PIMENTEL; OLIVER; UCHÔA-FIGUEIREDO, 2011). Nesse âmbito, a publicação das diretrizes curriculares apontou para a necessidade de uma formação geral e específica de profissionais, para serem aptos a trabalhar em diferentes contextos, segundo as realidades locais e em serviços de diferentes níveis de atenção, incluindo a APS, como possível cenário de formaçáo, pesquisa e extensão para a área (OLIVER et al., 2012; BRASIL, 2002).

$\mathrm{Na}$ prática, essas mudanças vêm encontrando desafios, devido à história da formação profissional ser realizada em espaços de reabilitação e às singularidades dos serviços em obedecer a uma lógica assistencial e não necessariamente estarem envolvidos com a ordenação da formação dos profissionais. Além disso, ocorrem dificuldades quanto à definiçâo de seu caráter generalista, visto que esse não seria apenas um generalista do campo da saúde, mas um generalista capaz de atuar em diferentes campos, como nos contextos sociais, na educação, no trabalho e na geração de renda, e na cultura (PAN, 2014). 
Em relação ao trabalho de terapeutas ocupacionais na APS, temos o profissional contemplado em dispositivos que, a depender da composição de suas equipes, poderá contribuir para a integralidade do cuidado na APS. Esses dispositivos estão integrados à Estratégia de Saúde da Família (ESF) e a toda rede de atençáa à saúde, podendo o terapeuta ocupacional compor as equipes em Unidades Básicas de Saúde (UBS); nos Núcleos de Apoio à Saúde da Família (NASF) (BRASIL, 2008), e nas equipes de Consultório na Rua (CnR) (BRASIL, 2012a) e de Atendimento Domiciliar (AD)/Programa Melhor em Casa (BRASIL, 2013).

Diante das possibilidades de inserção nesse nível assistencial, Rocha, Paiva e Oliveira (2012), ao refletirem sobre a terapia ocupacional na APS, alegaram a necessidade de maior clareza e percepção do objeto de estudo, dos processos de intervenção, das tecnologias e das possibilidades da terapia ocupacional nesse campo, tanto nos âmbitos teórico e acadêmico como na formação e na prática profissional. Aliado a essas necessidades, o primeiro - e talvez o maior dos desafios - seja ampliar o espectro de intervençôes e construir os processos de trabalho da terapia ocupacional baseados no território, junto a sujeitos coletivos e individuais, e aos dispositivos de APS. Isso se faz necessário porque a formação do profissional ainda hoje é essencialmente centrada no indivíduo (SOUZA, 2012).

Nesse sentido, considera-se fundamental conhecer mais profundamente as diferentes experiências de formação profissional para e na APS, assim como as proposiçôes teóricas dos atores que estáo envolvidos nos processos formativos. Ao mesmo tempo, é necessário sensibilizar os profissionais em atividade a refletir, por meio de pesquisas e construções teóricas, suas práticas profissionais na APS (OLIVER et al., 2012). Essa publicização das experiências na APS será uma das formas de subsidiar a formação de profissionais para intervir nesse contexto (SOUZA, 2012).

Dessa forma, o objetivo do presente artigo é descrever e analisar a orientação teórica e os cenários de prática na formação de terapeutas ocupacionais na APS. Esses elementos devem ser compreendidos, discutidos e relacionados às Diretrizes Curriculares Nacionais para Cursos de Terapia Ocupacional (BRASIL, 2002) e às reflexóes sobre esse campo profissional.

\section{Método}

O estudo caracteriza-se como descritivo e exploratório de abordagem qualitativa, em que buscamos a análise das múltiplas realidades (SAMPIERI; COLLADO; LUCIO, 2013) expressas por 17 docentes, caracterizadas na Tabela 1, e que são responsáveis pela formação de terapeutas ocupacionais para APS, de cinco cursos públicos e quatro cursos privados de terapia ocupacional, do Estado de São Paulo.

O Estado de São Paulo é aquele que possui o maior número de cursos ativos do país; são 14 cursos de terapia ocupacional, sendo cinco cursos públicos e nove cursos privados, de um total de 43 cursos públicos e privados em funcionamento no Brasil, no ano de 2015. É neste estado que também se desenvolve o curso público mais antigo do país, em funcionamento desde o ano de 1956 (PALM, 2012; BRASIL, 2015a).

A construção dos dados de campo se deu pela identificação inicial dos cursos do país em levantamento de Palm (2012) e por meio do portal e-MEC (BRASIL, 2015a), além da elaboração de um instrumento de pesquisa: o Roteiro de Entrevista com Docente responsável pela formação para a APS. Esse roteiro foi previamente construído com a contribuiçấo de sete juízas, que possuem experiência no campo da pesquisa, ensino e prática profissional, relacionados aos campos da APS, da formação de profissionais de saúde e da formação de terapeutas ocupacionais.

A partir de autorização de participação na pesquisa de nove dos catorze cursos de terapia ocupacional em funcionamento no Estado de Sáo Paulo, no ano de 2015, foi contatado cada coordenador dos nove cursos, que indicou docentes que realizavam a formação de terapeutas ocupacionais para APS, o que levou à participaçáo, no estudo, de 17 docentes.

O processo de construção dos dados foi realizado nas instituiçóes de ensino dos participantes da pesquisa. Assim, após a leitura e a assinatura do Termo de Consentimento Livre e Esclarecido (TCLE), foram registradas, em gravador de áudio, as 17 entrevistas, num total de 11 horas e 26 minutos. Essas entrevistas foram transcritas, revisadas, organizadas e armazenadas em banco de dados. As transcriçôes foram encaminhadas às participantes via correio eletrônico a fim de possibilitar a análise de seus conteúdos e, se necessário, modificar algo que se julgasse pertinente. Apenas duas docentes recomendaram mudanças na transcrição, mas não houve alteraçôes significativas, que modificassem o conteúdo de suas contribuiçôes iniciais.

Por fim, foi realizada a leitura exaustiva do banco de dados, bem como o tratamento do material construído em campo e a categorização de temas associados ao objetivo do estudo, em um sistema de categorias empíricas formuladas à medida que 
Tabela 1. Caracterização das docentes conforme ano de graduação, titulação e tempo de vinculação ao ensino na APS.

\begin{tabular}{|c|c|c|c|c|}
\hline $\begin{array}{c}\text { Ano de } \\
\text { graduação em } \\
\text { TO das docentes }\end{array}$ & Participantes $^{2}$ & $\begin{array}{c}\text { Pós-Graduação de maior } \\
\text { nível }\end{array}$ & $\begin{array}{l}\text { Tempo da docente } \\
\text { na IES e tempo } \\
\text { vinculado à } \\
\text { formação para } \\
\text { APS }\end{array}$ & $\begin{array}{c}\text { IES } \\
\text { Pública ou } \\
\text { privada/ano de } \\
\text { criação do curso }\end{array}$ \\
\hline 1979 & Docente 6 & $\begin{array}{l}\text { Doutorado em Psicologia } \\
\text { Social - } 1999\end{array}$ & 31 anos/ 16 anos & $\begin{array}{l}\text { IES C } \\
\text { pública/1956 }\end{array}$ \\
\hline 1980 & Docente 17 & $\begin{array}{l}\text { Doutorado em Medicina } \\
\text { (Saúde Mental) - } 2000\end{array}$ & 13 anos/13 anos & $\begin{array}{l}\text { IES D } \\
\text { pública/2002 }\end{array}$ \\
\hline 1981 & Docente 15 & $\begin{array}{l}\text { Doutorado em Filosofia da } \\
\text { Educação - } 2012\end{array}$ & 17 anos/10 anos & $\begin{array}{l}\text { IES I } \\
\text { privada/1998 }\end{array}$ \\
\hline 1983 & Docente 8 & $\begin{array}{l}\text { Doutorado em Engenharia } \\
\text { de Produção - } 2004\end{array}$ & 10 anos/8 anos & $\begin{array}{l}\text { IES D } \\
\text { pública/2002 }\end{array}$ \\
\hline 1985 & Docente 7 & $\begin{array}{l}\text { Doutorado em Saúde } \\
\text { Coletiva - } 2000\end{array}$ & 29 anos/29 anos & $\begin{array}{l}\text { IES C } \\
\text { pública/1956 }\end{array}$ \\
\hline 1986 & Docente 2 & $\begin{array}{l}\text { Doutorado em Psicologia } \\
-2009\end{array}$ & 5 anos $/ 5$ anos & $\begin{array}{l}\text { IES A } \\
\text { pública/2006 }\end{array}$ \\
\hline 1988 & Docente 1 & $\begin{array}{l}\text { Doutorado em Medicina } \\
\text { Preventiva - } 2012\end{array}$ & 1 ano/8 meses & $\begin{array}{l}\text { IES A } \\
\text { pública/2006 }\end{array}$ \\
\hline 1997 & Docente 5 & $\begin{array}{l}\text { Doutorado em Saúde } \\
\text { Coletiva - } 2014\end{array}$ & 1 mês/ 1 mês & $\begin{array}{l}\text { IES B } \\
\text { pública/1978 }\end{array}$ \\
\hline 1999 & Docente 3 & $\begin{array}{l}\text { Doutorado em Saúde } \\
\text { Coletiva - } 2013\end{array}$ & 8 meses $/ 8$ meses & $\begin{array}{l}\text { IES B } \\
\text { pública/1978 }\end{array}$ \\
\hline 2001 & Docente 4 & $\begin{array}{l}\text { Doutorado em Saúde } \\
\text { Pública - } 2008\end{array}$ & 10 anos/10 anos & $\begin{array}{l}\text { IES B } \\
\text { pública/1978 }\end{array}$ \\
\hline 2001 & Docente 9 & $\begin{array}{l}\text { Doutorado em } \\
\text { Educação - } 2013\end{array}$ & 2 anos $/ 2$ anos & $\begin{array}{l}\text { IES E } \\
\text { pública/2003 }\end{array}$ \\
\hline 2002 & Docente 14 & $\begin{array}{l}\text { Mestre em Psicologia da } \\
\text { Saúde - } 2011\end{array}$ & $\begin{array}{l}2 \text { anos e } 6 \text { meses } / 1 \\
\text { ano }\end{array}$ & $\begin{array}{l}\text { IES H } \\
\text { privada/2006 }\end{array}$ \\
\hline 2002 & Docente 12 & $\begin{array}{l}\text { Especialização em } \\
\text { Administração de Recursos } \\
\text { Humanos - } 2008\end{array}$ & 7 anos $/ 6$ meses & $\begin{array}{l}\text { IES H } \\
\text { privada/2006 }\end{array}$ \\
\hline 2005 & Docente 11 & $\begin{array}{l}\text { Especialização em } \\
\text { Docência do Ensino } \\
\text { Superior - } 2009\end{array}$ & 6 anos $/ 3$ anos & $\begin{array}{l}\text { IES G } \\
\text { privada/2005 }\end{array}$ \\
\hline 2007 & Docente 13 & $\begin{array}{l}\text { Especialização em } \\
\text { Tecnologia Assistiva - } 2012\end{array}$ & 3 anos $/ 3$ anos & $\begin{array}{l}\text { IES H } \\
\text { privada/2006 }\end{array}$ \\
\hline 2008 & Docente 10 & $\begin{array}{l}\text { Doutorado em Educação } \\
\text { Especial - } 2015\end{array}$ & $\begin{array}{l}1 \text { ano e } 6 \text { meses } / 6 \\
\text { meses }\end{array}$ & $\begin{array}{l}\text { IES F } \\
\text { privada/2012 }\end{array}$ \\
\hline 2010 & Docente 16 & $\begin{array}{l}\text { Mestre em Saúde } \\
\text { Pública - } 2013\end{array}$ & 1 ano/6 meses & $\begin{array}{l}\text { IES I } \\
\text { privada/1998 }\end{array}$ \\
\hline
\end{tabular}

iam sendo encontradas na leitura das entrevistas (BARDIN, 2011).

Para este artigo, foram selecionadas as seguintes categorias: orientação teórica - conteúdos essenciais à formação graduada do terapeuta ocupacional para a APS e o acompanhamento dos (as) estudantes em cenários de prática, e a influência das modalidades de gestão de serviços de APS na formação graduada de terapeutas ocupacionais.

Os dados construídos foram analisados à luz das Diretrizes Curriculares Nacionais do Curso de
Graduação em Terapia Ocupacional Brasil (2002) e dos referenciais teóricos e metodológicos da terapia ocupacional e da Saúde Coletiva, além das pesquisas e evidências científicas produzidas no campo da formação em saúde e em terapia ocupacional.

A pesquisa foi submetida ao Comitê de Ética em Pesquisa da Universidade Federal de Sáo Carlos, UFSCar, em conformidade com os princípios da Resolução n466 (BRASIL, 2012b) e teve parecer favorável à sua realização (Protocolo: 990.200, 14/04/2015). 


\section{Resultados e Discussão}

\subsection{Orientação teórica: conteúdos essenciais à formação graduada do Terapeuta Ocupacional para a APS}

Dentre os conteúdos teóricos, as docentes estabeleceram como essenciais à formação tanto conhecimentos relacionados ao campo da Saúde Coletiva como específicos do núcleo da terapia ocupacional. Apontaram o importante marco internacional de Alma Ata (1978), o estudo da Reforma Sanitária e a institucionalização do SUS como elementos teóricos e práticos estruturantes para o cuidado na APS.

Primeiro conhecer o que é a atenção primária, tanto o movimento internacional, a questão de Alma Ata, o próprio histórico da formação do SUS (Docente 1 - IES A).

Também foram indicados caminhos para a formação do terapeuta ocupacional no campo da compreensão crítica do SUS e da APS.

Eu acho essencial você levar o estudante a ter uma compreensão do sistema como um todo, menos do que uma ideia de que o SUS é para uma população que não tem acesso a outras formas de saúde [que eu acho que essa ainda é uma ideia predominante em muitos cursos, a de que trabalhar no SUS é trabalhar com pessoas que não tem dinheiro para comprar outras coisas] o que coloca ai no pensamento uma certa forma de ver essa população e o próprio trabalho. Então eu acho que colocar o estudante em contato com o que é o SUS, da história que gestou o SUS, dos principios que foram elaborados a partir de uma certa critica ao modelo anterior. O SUS não é apenas um sistema do ponto de vista do seu funcionamento de instituiçóes e tal, mas como um projeto de cidadania, é um projeto que, gestado a partir de uma crítica à sociedade, se coloca desse modo (Docente 7 - IES C).

Como apontado, se faz necessário conhecer as influências e a organização do SUS e da APS, visto que, em determinadas situaçóes, esse desconhecimento dos profissionais de saúde e dos usuários, como ainda acontece no Brasil, não favorece o reconhecimento da sua devida importância (CAMPOS et al., 2008).

Compreender as dificuldades e desafios de um sistema de saúde universal e público para sua organização e funcionamento não parece ser diferente para o contexto de formação dos terapeutas ocupacionais para APS, como abordado a seguir:
Conhecer a politica pública de saúde, [é estudar o SUS e identificar o nosso papel em cada lugar] entender como é que os serviços estâo estruturados de fato, por exemplo, quando vamos trabalhar com algumas comunidades, elas não conseguem entender a diferença entre um serviço de Pronto Atendimento e uma UBS, por exemplo, muitas vezes, nós profissionais também não sabemos fazer essa diferença (Docente 12 - IES H).

Para a sólida e crítica compreensão da APS no SUS, há necessidade de estudo teórico em profundidade sobre política pública, sobre a sociedade e o controle social, como podemos identificar, nos seguintes excertos:

É fundamental a discussão sobre a questão da política de saúde e uma compreensáa da política pública, uma compreensäo teórica, uma compreensão que nos faça entender qual é o lugar da saúde nesta sociedade que tem essa contradição de uma mensagem mercadológica e prevalente do sistema privado de saúde e o direito constitucional da questão universal do direito à saúde... O estudo do funcionamento da sociedade, o estudo do papel do profissional nesta sociedade (Docente 4-IES B).

Eu acho que o aluno precisa ter uma formação politica, conhecer quais são as diretrizes para a organização da saúde no município, como se fazo controle social, precisa ter conhecimento da história da saúde pública e do SUS (Docente 15 - IES I).

Alia-se à formação para APS, a compreensão da educação popular e do conhecimento do território, como propóem os relatos abaixo.

Usar da educação popular, conhecer esse território, conhecer a cultura desse território para desenvolver açōes junto com a população, a comunidade. Pensar território, como um instrumento que usamos na saúde, que é a territorialização (Docente 8 - IES D).

Pensar o sujeito no território, as questôes que ele vive com a sua patologia, as dificuldades, que nem sempre estão voltadas para a doença, suas relaçōes com as pessoas do bairro, ao seu papel social (Docente 15 - IES I).

Além disso, a APS aborda os problemas mais comuns na comunidade, oferecendo serviços de prevenção, cuidado e reabilitação. Ela integra a atenção quando há mais de um problema de saúde e lida com o contexto no qual a doença existe, e influencia a resposta das pessoas a seus problemas de saúde. O cuidado à saúde na APS fica próximo do contexto das pessoas, uma posição melhor para avaliar 
o papel dos múltiplos e interativos determinantes da doença e da saúde (STARFIELD, 2002).

Para essa abordagem da APS, faz-se necessário promover, na formação dos terapeutas ocupacionais, a compreensão de diferentes temas, também indicados pelas Docentes.

A palavra acolhimento mais do que em qualquer outro lugar eu acho que na atenção básica para a porta de entrada é fundamental. A questão da longitudinalidade é um desafio enorme, e eu acho que é uma coisa para pensarmos também, como um instrumento muito importante na atenção básica (Docente 7 - IES C).

A compreensão da continuidade do cuidado, atenção comunitária e familiar, do trabalho em equipe, da necessidade do usuário, da intersetorialidade e do conceito de integralidade (Docente 1 - IES A).

Nesse sentido, é importante compreender que não existe alta nos processos de cuidado da APS, pois a vinculação do usuário com a equipe deverá ser fortalecida todo o tempo, já que esta é responsável pela saúde de uma família e pela longitudinalidade do cuidado (SOUZA, 2012).

Em relação à formação, é um grave erro basear a atuação e a formação profissional na APS apenas nos aspectos do campo da Saúde Coletiva, visto que a terapia ocupacional tem muito a contribuir enquanto núcleo específico, principalmente no que concerne ao apoio às equipes no cuidado a famílias de maior risco e vulnerabilidade, por meio da articulação intersetorial, da escuta, do vínculo, do diálogo, do cuidado aproximado e da utilização do que se tem disponível para realização do cuidado na APS. Dessa forma, o cuidado a ser realizado pode ser chamado de específico, mas não especializado. Isso quer dizer que a especificidade da profissão não é perdida na APS, pois, ao contrário, ela é mantida e constantemente refletida (SOUZA, 2012).

No entanto, para a construção dessa especificidade, nota-se ainda que o campo da APS e a terapia ocupacional possuem uma literatura incipiente, mas com uma tendência de maior acúmulo em pesquisas, intervençóes e desenvolvimento específicos (BASSI; MALFITANO; BIANCHI, 2012). Essa conjuntura corrobora com o seguinte relato:

Na questão da terapia ocupacional, temos pouca literatura, eu sinto que temos mais artigos na $R B C$ e no trabalho com pessoas com deficiência do que na saúde mental na atenção primária (Docente 1 - IES A).
No bojo do pequeno, mas crescente número de publicações sobre a terapia ocupacional na APS, convém destacar as especificidades desse núcleo profissional, que se constitui como um campo emergente de atuaçáo do profissional (BAISSIA; MAXTA, 2013).

Cabe destacar que os saberes do campo de conhecimento da Epidemiologia, da Antropologia, da Saúde Coletiva, de referenciais da Reabilitação Psicossocial e da Reabilitação Baseada na Comunidade (RBC) têm composto os referenciais teóricos e metodológicos de processos formativos e das práticas em terapia ocupacional na APS (OLIVER; AOKI; CALDEIRA, 2013; CALDEIRA, 2009).

Além destes, as docentes indicaram especificidades do núcleo profissional da terapia ocupacional e elencaram conteúdos essenciais à formação, como podemos perceber a seguir.

Dentro da terapia ocupacional, trabalhar o cotidiano, o uso do tempo, ocupaçóes significativas (Docente 1 - IES A).

Trazer conceitos que nos säos caros como o cotidiano, como a vida ocupacional desses sujeitos e pensar isso no território (Docente 3 - IES B).

Outra coisa que eu acho que é bem importante é a questão da formação em relação à compreensão do que é cotidiano e as atividades de vida diária (Docente 5 - IES B).

A vida cotidiana aparece como um conteúdo para a formação do terapeuta ocupacional na APS, visto que esse nível assistencial é parte essencial do cuidado em saúde da população, ao mesmo tempo em que a vida cotidiana é objeto de estudo e de intervenção da terapia ocupacional (SILVA; MENTA, 2014).

É possível entender que interessa à terapia ocupacional o que as pessoas fazem, como usam o tempo, aonde vão, quais são seus desejos, como o contexto social facilita ou dificulta o engajamento das pessoas em diferentes atividades, enfim como se constrói a vida cotidiana dos sujeitos. Cada cotidiano é particular e é construído conforme a singularidade e a realidade vivida no contexto social (SALLES; MATSUKURA, 2013). Assim, a compreensão, a construção e a transformação da vida cotidiana podem se apresentar como recursos terapêuticos-ocupacionais para o cuidado na APS, já na formação graduada.

As docentes informaram sobre diferentes conteúdos necessários à formação para APS, o que pode estar ligado tanto ao caráter generalista e específico do campo como ao histórico da profissão e de suas 
intervenções no âmbito da reabilitação física e da saúde mental.

[Sobre o estágio em deficiência física] Para $o$ aluno se construir na APS, eu acho que ele precisa trazer tudo o que ele tem. Ele tem que trazer o que ele sabe de dinâmica de grupo, o que ele sabe de saúde mental, o que ele sabe de relaçóes familiares o que ele sabe de atividade, o que ele sabe de órtese, o que ele sabe de Bobath, manipulaçāo corporal, o que ele sabe de quadros clínicos. É um mosaico, é uma composição. Eessa composição só pode ser possivel diante da necessidade do usuário (Docente 6 - IES C).

Eu posso saber o que é TO, mas eu tenho que saber para que a profissão serve, então vejo que o terapeuta ocupacional vai instrumentalizar a autonomia do sujeito também [na APS] vai criar espaços de vivência e de bem-estar nós vamos promover o cinema, mas temos que saber fazer uma escuta $d a$ depressão, é um cuidado biopsicossocial, mas com muito respeito ao cultural (Docente 17, IES D).

Essa construção generalista é essencial à formação, porque vai embasar as práticas específicas do terapeuta ocupacional no interior do serviço de APS, nos ambientes domiciliares e nos contextos comunitários (BAISSIA; MAXTA, 2013). Dessa maneira, o terapeuta ocupacional na APS é responsável pelo planejamento, gerenciamento, coordenação e avaliação das ações específicas de terapia ocupacional desenvolvidas em serviços de APS, no domicílio e na comunidade. Assim, ele desenvolve açóes de cuidado junto a diferentes populaçôes, como aquelas que apresentam deficiência, sofrimento psíquico, alterações no desenvolvimento humano, vulnerabilidade social e/ou que possuem dificuldade na realização de suas atividades do cotidiano, sejam estas lúdicas, laborais ou de circulação e interação social, entre outras (ROCHA; PAIVA; OLIVEIRA, 2012).

Distintos são os conteúdos essenciais à formação e a estes estão articulados à compreensão das políticas públicas de saúde da APS e dos dispositivos desse nível assistencial, que contemplam a presença do terapeuta ocupacional, como, por exemplo, a UBS, o NASF, o Consultório na Rua e a Atenção Domiciliar. Além disso, conforme reafirmam as docentes, é necessário conhecer as ferramentas de trabalho desse campo, como o apoio matricial, a clínica ampliada e o Projeto Terapêutico Singular (PTS).

Compreender os dispositivos da APS que o TO está inserido do ponto de vista da portaria ministerial, o que seria o NASF, o consultório na rua e a atenção domiciliar. É imprescindivel para o TO entender o que é apoio matricial, porque esse fundamentalmente éo conceito que estamos sendo convidados a ocupar para Atenção Básica. Saber o que é Estratégia de Saúde da Família, território e integralidade, clínica ampliada, campo e núcleo, equipe de referência, Projeto Terapêutico Singular (PTS), por exemplo, qual é a singularidade da TO em relação a esse conceito. Na construção do PTS pensamos como organizar um plano de intervenção terapêutico ocupacional (Docente 3 - IES B).

$O$ estudante tem que ter noção dos programas ministeriais para ele poder se inserir enquanto profissional. $O$ estudante precisa ter ideia sobre o processo saúde-doença-cuidado, sobre a clínica ampliada, sobre o PTS. Ter noção do que é e quais são os equipamentos de saúde, como é a gestão desse equipamento, conhecer a rede, como esse cuidado é dentro da rede (Docente 2 - IES A).

Há, no Brasil, uma compreensão ampliada das atribuiçóes da APS no Brasil, demonstrada na Portaria no 2.488 de 2011 (BRASIL, 2011). Essa ampliação veio acompanhada de maior inserçáo de diferentes profissionais em dispositivos de APS, o que amplia as novas formas do agir e cuidar do profissional, e que insere tecnologias próprias a esse nível assistencial (ROCHA; PAIVA; OLIVEIRA, 2012).

Isso acontece em decorrência de que a APS traz uma dupla carga de complexidade: desafia as categorias profissionais que atuam na área da saúde a reestruturar seu modelo de formação, a fim de alinhar o perfil profissional às necessidades da populaçáo na APS, e exige clara definição das competências específicas de cada profissão, de modo que os limites de cada área sejam respeitados, promovendo assim $o$ acesso da populaçáo a tais expertises de maneira interprofissional (ROCHA; PAIVA; OLIVEIRA, 2012).

Outro aspecto levantado pelas docentes foi a formação em terapia ocupacional para APS e a interface com o campo teórico-prático da terapia ocupacional social.

Sempre procuro afirmar qual diferença faz ter um TO na APS, qual é o núcleo da TO nesse espaço da APS, que é tão generalista, que tem as fronteiras tão borradas (Docente 3 - IES B).

Então, é difícil discutirmos o que é social, o que é Atenção Primária em Saúde, porque têm conteúdos semelhantes, o estudante tem que entender que tem coisas que são especificas de uma área e de outra, mas têm que entender as articulaçôes possiveis entre esses dois campos (Docente 8 - IES D).

A problemática da heterogeneidade de conceituação do campo social na terapia ocupacional e a sobreposição com outro campo de atuação - que tem recebido 
grande destaque para a formação prática em saúde, a APS - apresentam repercussóes na formação teórica e prática. Dessa forma, é válido entender que o território e a situação de vulnerabilidade social não são suficientes para definir uma ação técnica profissional. Assim, faz-se necessário que se analisem com profundidade os objetivos e os métodos das intervençôes no campo social e na APS, e, igualmente, os saberes e os conhecimentos que norteiam as açóes em cada área (LOPES; PAN, 2013).

Nessa perspectiva, a terapia ocupacional pode contribuir para desenvolver açôes para a minimizaçáo e/ou resolução de situaçôes de vulnerabilidade e risco social em cada território de abrangência na APS, com base em açôes territoriais e intersetoriais direcionadas às necessidades individuais e coletivas (ROCHA; PAIVA; OLIVEIRA, 2012).

Outro conteúdo essencial à formação para APS foi aquele relacionado ao trabalho e manejo de grupos. Segundo Ballarin (2015), é fundamental o aprendizado para trabalhar com grupos, já que se espera que o terapeuta ocupacional tenha um acúmulo de habilidades específicas para compreender, organizar e coordenar grupos, seja atuando como membro de uma equipe, como gestor ou na assistência em saúde, educação ou em contextos sociais.

Na Atenção Primária você trabalha com grupos, você trabalha com a comunidade, essa habilidade também é bastante importante. Disso decorre também a habilidade de trabalhar em equipe multiprofissional (Docente 5 - IES B).

Dessa maneira, as diversas atividades individuais ou grupais utilizadas pela terapia ocupacional na APS têm, como propósito, tanto o conhecimento como as possibilidades colocadas para a reorganizaçáo e transformação do cotidiano, buscando promover a máxima participação na vida pessoal e social (ROCHA; PAIVA; OLIVEIRA, 2012).

\subsection{O Acompanhamento dos (as)} estudantes em cenários de prática e a influência das modalidades de gestão de serviços de APS na formação graduada de Terapeutas Ocupacionais

A descrição das docentes sobre o acompanhamento dos (as) estudantes no cenário real da APS favoreceu o entendimento das estratégias presentes nesse componente teórico-prático e da sua relevância para a formação do terapeuta ocupacional na APS.
A inserção de estudantes no cenário da APS vem ocorrendo com fragilidades decorrentes das várias dificuldades para o estabelecimento de parceria entre os serviços de saúde e a academia, o que tem dificultado uma construçáo efetiva do processo de aprendizagem, nos diferentes cursos que atuam nesse contexto assistencial (CORÁCIO et al., 2014).

Também em produçôes recentes sobre a formação de terapeutas ocupacionais para o campo da saúde mental, está posto esse desafio, devido à carência de recursos e à dificuldade em estabelecer parcerias entre IES e os serviços; porém, a integração ensino-serviço é estratégica para a formação do terapeuta ocupacional, principalmente pela potência de vivenciar os desafios e contradiçôes que os serviços proporcionam para o maior exercício da prática. Além disso, esta integração demanda por um profissional que contribua na busca de soluções que atendam, além das necessidades da formação, às prioridades assistenciais tanto do território quanto do SUS e das políticas públicas (LINS; MATSUKURA, 2015a, b).

Em relação à integração ensino-serviço na APS, as docentes mencionam que esse cenário de formação é um espaço de vulnerabilidade.

Estamos em áreas de maior vulnerabilidade, em algumas unidades de saúde da família (Docente 1 - IES A).

Estamos em uma unidade que é de um bairro socialmentelculturalmente considerado prejudicado porque tem a questão do tráfico (Docente 9-IES E).

Temos o estágio que é específico na Unidade Básica de Saúde, em uma regiāo bem empobrecida da cidade (Docente 11 - IES G).

Quanto ao acompanhamento dos alunos, tenho tentado sensibilizá-los para esse contexto [referindose ao contexto vulnerável]. Como cuidar das pessoas (Docente 15 - IES I).

O local de prática é no território, aqui próximo à universidade, que é um território bastante vulnerável em termos de acesso (Docente 16 - IES I).

As docentes não indicaram referenciais teóricos de suas reflexóes sobre essa temática e, para essa compreensão, concordamos com Castel (2008), que, ao discorrer sobre a questão social, declara que a vulnerabilidade é fruto do estabelecimento de um sistema de relações entre a degradação da situação econômica e social, e a desestabilização dos modos de vida dos grupos, que estão face a face com as problemáticas sociais. 
Castel (2008) entende que o espaço social é composto por zonas, marcadas pela situaçáo de vulnerabilidade ou integração, em que as pessoas vivem. Assim, na zona de integração, há trabalho permanente e rede de suporte social forte; na zona de vulnerabilidade, há relação entre a precariedade do trabalho e a fragilidade na rede de suporte social; na zona de desfiliação, existe ausência de trabalho e de relaçóes sociais, e na zona de assistência, tornam-se explícitas a expulsão do trabalho e a dificuldade de inserçáo social. Esse autor enfatiza que a precarização do trabalho produz o processo que alimenta a vulnerabilidade social e produz, no final do percurso, o desemprego e a desfiliação, e que o Estado torna-se o principal suporte e a principal proteção à vulnerabilidade.

Oliveira e Furlan (2008) também afirmam que o conceito de vulnerabilidade de Castel é útil para pensarmos como as práticas de saúde têm se organizado - e podem se organizar - nos territórios e nos serviços destes participantes. Dessa forma, o estudo desse conceito é favorável ao desenvolvimento de processos formativos na APS, já que esse nível assistencial se encontra próximo à vivência social das pessoas.

Diante disso, é importante refletir sobre a orientação da formação graduada para a APS, já que levar os estudantes ao serviço de APS os faz perceber uma realidade da qual, às vezes, estáo distantes. Essa aproximação pode provocar, nos alunos, a construção de um cuidado higienista pelo encontro entre pessoas vindas de contextos diferentes, o que torna necessário problematizar esse percurso formativo na graduação (CECCIM, 2014), com discussōes teóricas sólidas sobre o que sejam as realidades e a vulnerabilidade vivenciadas pela população e pelos estudantes durante a formação.

Esse cuidado higienista pode ser provocado pelo que Freire (1983) chamou de invasão cultural, em que um sujeito que invade o espaço histórico-cultural do outro sobrepóe sua visão de mundo aos indivíduos por meio de relaçóes autoritárias. Dessa maneira, a saída para esse processo perverso seria promover a comunicaçáo e o diálogo, de uma maneira que estes não possam ser rompidos pela relação entre pensamento-linguagem-contexto ou realidade; entáo, deveria haver maior comunicação entre a universidade e a populaçáo, nesse contato dos estudantes com os serviços de APS e seus territórios.

Em decorrência desse contato dos alunos com diferentes territórios da APS, algumas docentes destacaram esse cenário como promotor de possibilidades na formação pelo fato de provocar o contato com: o saber popular; o pensar a saúde como direito público; a necessidade de articulaçóes intersetoriais, e a ampliação do conceito de saúde.

Outro aspecto é você entrar em contato direto com o saber popular dos agentes comunitários de saúde, com uma equipe interdisciplinar que está pensando problemáticas que nem sempre a TO pensou (Docente 3 - IES B).

De fato, o SUS é recente, mas observamos poucos esforços na sua defesa. Acho que essa é uma questão importantíssima na formação do terapeuta ocupacional, que vendo os outros estudantes das outras áreas, a gente está na frente. Pelo menos é o que eu vejo aqui (Docente 15 - IES I).

Temos parceria com o CRAS que é muito recente, aconteceu na semana passada uma reunião entre a psicóloga responsável do CRAS e nós [do estágio de TO na APS] (Docente 10 - IES F).

É engraçado, no começo, a gente fazia uma questão muito voltada ao atendimento, pensando em saúde, mas muito na questão física. E agora a gente já consegue ampliar esse olhar da terapia ocupacional para uma saúde em geral. Pensando na funcionalidade e na apropriação do indivíduo daquele espaço (Docente 13 - IES H).

Diante das consideraçóes apontadas, vemos que o aprendizado dos estudantes é proporcionado pela produção de encontros entre eles e as pessoas, as famílias e as comunidades. Esses encontros, na perspectiva de Bravo, Cyrino e Azevedo (2014), possibilitam a troca de saberes, percebendo o outro como portador de conhecimento distinto, caminho essencial para o desenvolvimento do cuidado qualificado na APS.

Esses encontros são ratificados como importantes pelas docentes.

O que eu acho essencial é um saber como se relacionar com o outro. Como realmente produzir um encontro, um encontro verdadeiro. E eu estou chamando um encontro verdadeiro exatamente como o Merhy fala, quero dizer, aquele encontro que afeta a ambos, que os dois saem de fato afetados, não é uma coisa (Docente 7 - IES C).

É preciso ter empatia e para ter empatia é preciso ter vivência na comunidade e respeito à diversidade (Docente 17, IES D).

Os encontros são mediados pelo acompanhamento docente ou de preceptores no contexto de formação prática na APS, em que estes podem provocar a formação do papel político do estudante, como enfatizado no seguinte excerto: 
Você tem que ter muito claro [no estágio de TO na APS] o papel do que é o SUS, e do papel político que os profissionais de saúde possuem na formação dos estudantes, não é um favor que eles estão fazendo, isso ajuda a qualificar essa assistência e está junto desses profissionais, é um papel do docente. $O$ docente tem que fazer um papel com os alunos e também com as equipes (Docente 1 - IES A).

O acompanhamento dos estudantes é realizado por docentes, preceptores e técnicos vinculados às IES, e, nesse sentido, as docentes relatam sua experiência.

Mostramos junto com os estudantes como é o atendimento da $\mathrm{TO}$ [para a equipe da ESF] por meio de casos, das atividades do cotidiano, da autonomia dentro de casa, do se locomover sozinho, então mostramos que não somos of fisioterapeuta, que temos um núcleo de conhecimentos. Não há a presença de terapeutas ocupacionais na rede de assistência na atenção primária, quem desempenha o papel docente são os professores (Docente 1 - IES A).

Eu trabalho junto com os estudantes mais dentro da unidade, dando apoio aos serviços e às açôes, então nós temos grupos dentro da unidade básica. [Trabalhamos] no domicílio, no território e dentro da unidade. Não tem preceptores, eu estou há aproximadamente 4 anos no estágio e não tenho muito tempo para outras coisas, por que o estágio consome muito tempo (Docente 2 - IES A).

O curso entende o espaço da APS como um espaço importante na formação, entendemos ainda, que a gente carece de recursos para implementar de uma forma mais efetiva, porque acaba contando só com os nossos recursos humanos, dois docentes envolvidos e uma técnica, mas não temos terapeuta ocupacional na rede e não temos terapeutas ocupacionais vinculados, por exemplo, à [IES D] que possa ser preceptor (Docente 8 - IES D).

Selecionamos alguns casos para fazer o plano terapêutico singular junto com os alunos, a gente divide tarefas, isso envolve não só os nossos alunos, envolve toda unidade - estão o agente de saúde e o trio gestor, a médica, a enfermeira, o dentista, as auxiliares de enfermagem. Todos acabam participando bastante das nossas intervençōes na unidade. Eles não têm a responsabilidade (TO do NASF), burocrática para estar, mas eles fazem parte também da nossa estratégia ali enquanto estágio (Docente 9 - IES E).

Os alunos não fazem nenhuma ação que não passe por mim [docente] ou que eu não tenha conhecimento. Eu que divido quem vai em qual casa, perfil de paciente com o perfil de aluno, nos grupos também todas as açöes desenvolvidas por eles, eles têm que bolar qual ação que vão desenvolver. $O$ acompanhamento dos estudantes é direto, nos atendimentos domiciliares cada dia eu vou com um aluno em uma casa, e assim eu vou passando aos poucos em todos (Docente 10 - IES F).

O acompanhamento também é realizado por preceptores. Observa-se que a presença dessa figura, no contexto de formação de terapeutas ocupacionais, é escassa, devido até mesmo à pequena inserção desses profissionais na APS. Esse aspecto é destacado nas exposiçōes:

Há presença de 6 TO na APS, duas no NASF e 4 em distritos de saúde nas USF. Os alunos têm formaçôes muito distintas dependendo do preceptor, porque esse preceptor vai estar refém daquela unidade que pode ser totalmente diferente da outra. As diferenças e singularidade entre as unidades são superimportantes e eu valorizo, mas, $e ́$, as possibilidades de formação, elas precisariam ser um pouco mais equalizadas, essa eu acho que é uma limitação e a outra limitação é que, de fato, como não há um plano da ação da TO na rede [e na APS], o plano da preceptoria, ele também fica fragilizado porque ai a gente tem preceptoras que participam muito ativamente do processo, $e$ outras, menos (Docente 3 - IES B).

Temos 2 TO do NASF na UBS [onde acontece o estágio], é bastante, mas, [elas não fazem supervisão dos alunos]. A técnica da [IES C], que faz esse papel de supervisionar. Não fizemos parceria com as TO do NASF, nós fizemos parceria com o NASF. Pensando no trabalho interprofissional (Docente 6 - IES C).

Frente ao processo de acompanhamento, as docentes identificaram desafios, tais como:

A equipe da ESF não sabe o que éTO (Docente 1 - IES A).

Dentro de uma unidade básica, não existe o lugar do terapeuta ocupacional (Docente 2 - IES A).

Na rede de APS do municipio, não temos terapeutas ocupacionais (Docente 17, IES D).

O nosso incômodo é porque são duas horas-aulas, então, assim, o máximo que o aluno consegue fazer é entrar em contato mesmo, que também é importante, as primeiras práticas são vivências. Essa relação com o usuário, o vínculo, a gente não consegue fazer muito, eu sinto falta desse espaço 
para a gente poder fazer essa articulação entre teoria e prática com o aluno (Docente 16 - IES I).

Questionamentos dos alunos [sobre a TO na APS]: Fazer visita domiciliar no paciente sem nenhum objeto de atividade prática, é terapia ocupacional? Então essas questóes vinham muito à tona e isso foi muito rico, muito produtivo (Docente 11 - IES G).

Não tinha TO na APS, o que dificultava muito também a nossa entrada e, assim, por mais que existissem essas limitaçóes, eu acho que, durante o processo que eu permaneci na supervisão [como docente] e tudo, foi muito proveitoso, a questão da terapia ocupacional (Docente 11 - IES G).

Segundo Corácio et al. (2014), há dificuldade no processo de formação dos profissionais que atuam no setor saúde: a) com relação ao número insuficiente de profissionais do serviço, não se consegue ter uma efetiva participação na formação dos estudantes; b) a organização técnico-política das unidades de saúde cria condiçôes para ausências prolongadas e sem substituição de profissionais nos serviços. Além disso, existem dificuldades na estrutura dos serviços que impossibilitam acolher as necessidades da formação dos profissionais: o estudante não consegue ver o sistema funcionar, não consegue ver resolubilidade, e ele vê uma demanda excessiva no serviço (CORÁCIO et al., 2014).

A formação requer uma mudança nas práticas das equipes de APS, ou seja, no modo como vem sendo estruturado o processo de trabalho, sendo este um dos "nós críticos" para a mudança do modelo tecno-assistencial de saúde no Brasil. E, por esse motivo, é importante que a formação esteja articulada ao processo de tomada de decisão nas políticas públicas de saúde (CORÁCIO et al., 2014).

Dessa forma, o processo de acompanhamento demonstra-se complexo, devido à diversidade de contextos sociais e de serviços. Essa realidade requer esforços de diversas ordens, para que haja equalização de interesses e perspectivas sobre a formação de terapeutas ocupacionais, tanto a partir das IES, com docentes e estudantes, como dos técnicos, dos preceptores, da comunidade e da gestâo municipal de saúde, a qual compartilha os espaços de seus serviços com a formação de diversos profissionais de saúde e que viabiliza a contrataçáo de profissionais para o campo da APS.

Tendo em vista o apresentado, é necessário também apontar as modalidades de gestão dos serviços que recebem os estudantes nos contextos de práticas na APS, em decorrência de que a aproximação entre os processos de gestáo pública descentralizada do SUS e a educação dos profissionais de saúde está assentada também sobre o desafio da gestáo pública do setor da saúde para ordenar políticas de formação, como prevê o SUS (CECCIM; FEUERWERKER, 2004).

As docentes participantes da pesquisa identificaram três modalidades de gestão dos serviços (Administração Pública; Organizaçôes Sociais e Fundaçôes das IES), nas quais são desenvolvidos a formação prática e os estágios profissionalizantes dos estudantes de terapia ocupacional na APS. Porém, não geraram uma discussão sobre se as diferentes formas de gestão dos serviços de APS comprometem a formação dos estudantes e o desenvolvimento do cuidado na APS. A ausência do debate entre as IES - que promovem a formação dos profissionais de saúde e a gestão dos sistemas e serviços, e que realizam o cuidado em saúde - é uma das fragilidades apresentadas também por Ceccim e Feuerwerker (2004).

Uma das modalidades de gestão é a administração pública dos serviços de APS e uma das docentes destacou a presença de espaços de construçáo conjunta para a formaçáo dos estudantes de terapia ocupacional, mesmo que, no contexto de sua fala, tenha relatado a quebra desses espaços devido à descontinuidade político-administrativa, fruto da alternância de comando político no município.

A organização dos serviços é via administração direta. Temos basicamente dois fóruns, que produzem a produção conjunta entre a instituição de ensino $e$ os serviços da APS, um deles é o encontro de preceptores, que fazemos mensalmente com todos os preceptores dividindo esse encontro em que parte da carga horária é destinada a discussóes pedagógicas, avaliação dos alunos, construção conjunta de ementas e temas, etc. E uma outra parte é utilizada para educação permanente dos preceptores desenvolvendo temas que eles escolhem para gente desenvolver na formação (Docente 3 - IES B).

A gestão da APS é via administração direta (Docente 10 - IES F).

Outra modalidade de administração dos serviços de APS apresentada pelas docentes foi a de gestão por Organizaçôes Sociais (OS), modalidade que se caracteriza pela desconcentração de serviços para a esfera não estatal (CARNEIRO JUNIOR; ELIAS, 2006), o que provoca contradiçóes para implementação do SUS.

Administração desses centros de saúde, da estratégia de saúde da família, ela é realizada por organizaçôes sociais infelizmente (Docente 11 - IES G). 
A gestão dos serviços é via OS (Docente 13 IES H).

A gestão do município é mista, existe algumas pessoas do município que sáo contratadas via concurso público, diretamente da prefeitura, e tem uma instituição também que acaba fazendo contratos terceirizados de alguns funcionários. Os profissionais do NASF são contratados por esta instituição, então eles não são concursados via prefeitura, outros profissionais que compóem a equipe da atenção primária é via essa organização social (Docente 9 - IES E).

Eu acho que no caso particular do municipio temos essa presença das OS, que, aliás, agora está passando por uma baita de uma crise, que é a questão das $O S$ em relação aos vários distritos. A história mostra que essas OS muitas vezes não tiveram a participação na construção do SUS, não fizeram parte de uma compreensão de um projeto como é SUS. Então elas não podem vir com essa perspectiva (Docente 7 - IES C).

Já a gestão da APS dos municípios das IES C, D e H é realizada pelas Fundaçôes das IES, que também administram os serviços de saúde e os Centros de Saúde Escola, como uma modalidade de serviço para atender tanto às demandas de formação de seus estudantes da área de saúde como também às demandas de assistência à saúde da população de seus territórios.

Muitos serviços próprios das instituiçōes acadêmicas estão estruturados de acordo com uma lógica própria e interna, mais vinculada às demandas da pesquisa, da extensão e do ensino do que às demandas reais, para funcionar como referência e contra referência à rede de serviços do SUS (CAMPOS et al., 2000). Sobre isso, uma das docentes relata um aspecto sobre a origem histórica desse modelo de gestão.

No começo quando se iniciou a negociação entre a IES e o municipio, tinha essa ideia de que a universidade sabe como fazer. Por que muitas $O S$ são ligadas hoje às universidades ou às instituiçôes de ensino, essa ideia inicial eu vi muito ela ser gestada nas instâncias em que eu participava alguns anos atrás [anos 1980-1990] (Docente 7 - IES C).

A gestão por OS é uma realidade em diferentes cenários de prática, conforme indicam as docentes.

A gestão é via administração direta. Mas, acho que a tendência é que alguns serviços sejam por administração de OS (Docente 1 - IES A).
A lógica é que a saúde coletiva seja organizada pelas Organizaçóes Sociais fica cada vez mais evidente na politica do municipio. O Conselho Municipal de Saúde é bastante retrógrado, a maioria dos conselheiros tem pouco conhecimento do SUS, não há participação popular, os estudantes desconhecem a existência do Conselho. E ai a população, claro que deseja ter seguro saude, é o sonho de todo brasileiro. Mesmo os estudantes universitários, a maioria desconhece elou nunca participou de reunião, nem mesmo foi a um serviço de saúde (Docente 15 - IES I).

A modalidade de gestão por OS está centrada no modelo gerencialista e na desresponsabilização do Estado para construir programas e políticas para atender uma parcela expressiva dos direitos sociais conquistados. Essa polarização entre a administração direta e a desresponsabilização estatal embotou a busca de alternativas que, respeitando os princípios e diretrizes da Reforma Sanitária e do SUS, fossem capazes de superar os problemas do cuidado à saúde e assegurassem efetividade, qualidade e eficiência nos serviços prestados pelo SUS, como também na formação de profissionais de saúde (PAIM; TEIXEIRA, 2007).

Já no campo da terapia ocupacional, Lopes et al. (2008) identificaram, como problemáticas, em relação à formação: a necessidade de discutir junto à gestão o aumento de técnicos, terapeutas ocupacionais, para executar as políticas sociais, além de que a frequente alternância na gestão pública é uma grande dificuldade para manutenção de projetos, convênios e parcerias para o ensino, o que é agravado com a privatização dos serviços.

Nesse sentido, a formaçáo dos profissionais de saúde tem permanecido alheia à organização da gestão e ao debate crítico sobre os sistemas de estruturação do cuidado. Assim, serão necessários novos mecanismos de luta pelo planejamento e gestão públicos para que os serviços possam ser cenários de aprendizagem do SUS e para o SUS (CECCIM; FEUERWERKER, 2004).

Há a necessidade de se rever essa relação entre as IES e os serviços de APS, para que o processo de formação possa ocorrer com o fortalecimento do currículo e da atenção em saúde; quanto a isso, as diretrizes para a celebração dos Contratos Organizativos de Ação Pública Ensino-Saúde (COAPES) podem fortalecer a integração entre ensino, serviços e comunidade, no âmbito do SUS. Os COAPES são estratégias de gestão recentes, que buscam garantir o acesso a todos os estabelecimentos de saúde sob a responsabilidade do gestor da área de saúde como cenário de práticas para a formação no âmbito da 
graduação e da residência em saúde, e estabelecer atribuiçóes das partes relacionadas ao funcionamento da integração ensino-serviço-comunidade (BRASIL, 2015b). Além disso, é necessário também rever a questão da gratificaçáo e da cobertura assistencial promovida pelo profissional do serviço, que é responsável pelos estudantes no campo de prática da APS (CORÁCIO et al., 2014).

\section{Conclusão}

O estudo indica a necessidade de se ampliar a reflexão nos meios acadêmicos e profissionais sobre os pressupostos teóricos apontados, tais como: o referencial de Alma Ata (1978); o estudo da Reforma Sanitária; a compreensão crítica do SUS e da APS, e de suas características enquanto nível assistencial de cuidado contínuo e de política social, e também da especificidade da profissão na APS, o que envolve o entendimento dos dispositivos que referenciam a participação do terapeuta ocupacional nas equipes profissionais da APS e de suas ferramentas de trabalho, já na formação graduada. Associados a esses conteúdos estão a apreensão crítica e sólida das causas e efeitos da vulnerabilidade social, e das múltiplas possibilidades de compreender e transformar a vida cotidiana, como também o contexto institucional que envolve os serviços, desde sua gestão à composição dos quadros profissionais. Esses conteúdos teóricos poderiam ser elementos a serem retomados nas discussóes necessárias sobre a revisão das Diretrizes Curriculares Nacionais para a área de terapia ocupacional, na qual a formação teórico-prática para a APS poderia ser mais bem dimensionada e explicitada.

Foi identificada uma pluralidade de serviços e desenhos de gestão da APS, em que se desenvolvem as estratégias de articulação teórico-prática, o que também compóe o mosaico de dificuldades para se realizar a formação para esse campo profissional. A realidade dos serviços indica diferentes compreensóes de prática profissional nesse nível assistencial, o que dificulta o cuidado em saúde da população e também prejudica a formação de estudantes de diferentes áreas profissionais. E, nesse sentido, há maior prejuízo para a terapia ocupacional devido à inserção de pequeno número desses trabalhadores na APS.

Cabe ressaltar que a gestáo dos serviços engloba questóes de ordem macropolítica sobre o papel do Estado na realização das políticas sociais e que a presença de diferentes modalidades de gestáo dos serviços da APS provoca rebatimentos também nas atividades de formação de terapeutas ocupacionais, o que, pelo caráter exploratório deste estudo, não foi possível dimensionar, demonstrando-se a necessidade de outras pesquisas que tragam à tona essa problemática.

Dessa forma, cabe também à categoria profissional (estudantes, docentes, trabalhadores e entidades representativas), o seu engajamento do ponto de vista político e técnico, para que haja condução de processos formativos de acordo com as necessidades em saúde da população, com serviços equânimes de APS, e que o terapeuta ocupacional valorize a implementação de tecnologias de cuidado compatíveis com os seus saberes e recursos terapêuticos ocupacionais, em direção ao acesso universal da população a diferentes práticas de cuidado integral à saúde, já a partir da APS.

\section{Referências}

BAISSIA, G.; MAXTA, B. S. B. Experiência da Terapia Ocupacional no cuidado familiar em um serviço de Atenção Primária em Saúde. Cadernos de Terapia Ocupacional da UFSCar, São Carlos, v. 21, n. 2, p. 413-422, 2013.

BALLARIN, M. L. G. S. A formação do terapeuta ocupacional: conversando sobre o ensino de grupos e em grupos. In: MAXIMINO, V.; LIBERMAN, F. (Org.). Grupos e Terapia Ocupacional: formação, pesquisa e açôes. São Paulo: SUMMUS, 2015. p. 27-47.

BARDIN, L. Análise de conteúdo. São Paulo: Ediçōes, 2011.

BARROS, D. D.; LOPES, R. E.; GALHEIGO, S. M. Novos Espaços: Novos Sujeitos: a terapia ocupacional no trabalho territorial e comunitário. In: CAVALCANTI, A.; GALVÃO, G. (Org.). Terapia Ocupacional: fundamentação \& prática. Rio de Janeiro: Guanabara Koogan, 2007. p. 354-363.

BASSI, B. G. C. Terapia Ocupacional na atenção básica à saúde no município de São Carlos: um enfoque nas pessoas com deficiência e nas pessoas com sofrimento mental. 2012. 134 f. Dissertação (Mestrado em Terapia Ocupacional) - Universidade Federal de São Carlos, São Carlos, 2012.

BASSI, B. G. C.; MALFITANO, A. P. S.; BIANCHI, P. C. O terapeuta ocupacional na Atenção Básica em Saúde: a representatividade em revistas e nos congressos brasileiros da área. Cadernos de Terapia Ocupacional da UFSCar, São Carlos, v. 20, n. 3, p. 443-454, 2012.

BRASIL. Lei no 9.394, de 20 de dezembro de 1996. Estabelece as Diretrizes e Bases da Educaçáo Nacional. Diário Oficial [da] República Federativa do Brasil, Brasília, DF, 23 dez. 1996.

BRASIL. Conselho Nacional de Educação Câmara de Educaçáo Superior. Resolução CNE/CES, no 6, de 19 de fevereiro 2002. Institui Diretrizes Curriculares Nacio- 
nais do Curso de Graduação em Terapia Ocupacional. Diário Oficial [da] República Federativa do Brasil, Brasília, DF, 04 mar. 2002.

BRASIL. Ministério da Saúde. Portaria GM no 154, de 24 de janeiro de 2008. Cria os núcleos de apoio à saúde da família. Diário Oficial [da] República Federativa do Brasil, Brasília, DF, 04 mar. 2008.

BRASIL. Ministério da Saúde. Portaria no 2.488, de 21 de outubro de 2011. Aprova a Política Nacional de Atenção Básica, estabelecendo a revisão de diretrizes e normas para a organização da Atenção Básica, para a Estratégia Saúde da Família (ESF) e o Programa de Agentes Comunitários de Saúde (PACS). Diário Oficial [da] República Federativa do Brasil, Brasília, DF, 24 out. 2011.

BRASIL. Ministério da Saúde. Portaria GM no 122, de 25 de janeiro de 2012. Define as diretrizes de organização e funcionamento das Equipes de Consultório na Rua. Diário Oficial [da] República Federativa do Brasil, Brasília, DF, 26 jan. 2012a.

BRASIL. Ministério da Saúde. Resolução no 466, de 12 de Dezembro de 2012. Aprova as diretrizes e normas regulamentadoras de pesquisas envolvendo seres humanos. Diário Oficial [da] República Federativa do Brasil, Brasília, DF, 13 dez. 2012 b.

BRASIL. Ministério da Saúde. Portaria GM no 963, de 27 de maio de 2013. Redefine a Atenção Domiciliar no âmbito do Sistema Único de Saúde (SUS). Diário Oficial [da] República Federativa do Brasil, Brasília, DF, 28 maio 2013.

BRASIL. Portal do e - MEC. Cidades@: São Carlos. Disponível em: <http://emec.mec.gov.br/>. Acesso em: 26 set. 2015 a.

BRASIL. Ministério da Saúde. Portaria Interministerial $\mathrm{n}^{\mathrm{o}} 1.124$, de 4 de agosto de 2015. Institui as diretrizes para a celebração dos Contratos Organizativos de Ação Pública Ensino-Saúde (COAPES), para o fortalecimento da integração entre ensino, serviços e comunidade no âmbito do Sistema Único de Saúde (SUS). Diário Oficial [da] República Federativa do Brasil, Brasília, DF, 5 ago. 2015b. Seção 1.

BRAVO, V. A. A.; CYRINO, E. G.; AZEVEDO, M. A. R. Ensino na atenção primária à saúde e as Diretrizes Curriculares Nacionais: o papel do projeto político-pedagógico. In: CYRINO, A. P.; GODOY, D.; CYRINO, E. G. (Org.). Saúde, Ensino e Comunidade: reflexôes sobre práticas de ensino na atenção primária à saúde. São Paulo: Cultura Acadêmica, 2014. p. 25-48.

CALDEIRA, V. A. Prática de terapia ocupacional em unidade básica de saúde na atenção às pessoas com deficiência. 2009. 180 f. Dissertação (Mestrado em Ciências da Reabilitação) - Universidade de São Paulo, São Paulo, 2009.

CAMPOS, F. E. et al. Caminhos para Aproximar a Formação de Profissionais de Saúde das Necessidades da Atenção Básica. Revista Brasileira de Educação Médica, Rio de Janeiro, v. 24, n. 3, p. 53-60, 2000.
CAMPOS, G. W. S. C. et al. Reflexôes sobre a atenção básica e a estratégia de saúde da família. In: CAMPOS, G. W. S. C.; GUERRERO, A. V. P. (Org.). Manual de Práticas de atenção básica: saúde ampliada e compartilhada. São Paulo: Aderaldo \& Rothschild Editores LTDA, 2008. p. 132-152.

CARNEIRO JUNIOR, N.; ELIAS, P. E. Controle público e equidade no acesso a hospitais sob gestão pública não estatal. Revista de Saúde Pública, São Paulo, v. 40, n. 5, p. 914-920, 2006.

CASTEL, R. As Metamorfoses da questão social: uma crônica do salário. Petrópolis: Vozes, 2008.

CECCIM, R. B. Compromissos do ensino da saúde com os desafios sociais. In: CYRINO, A. P.; GODOY, D.; CYRINO, E. G. (Org.). Saúde, Ensino e Comunidade: reflexóes sobre práticas de ensino na atenção primária à saúde. São Paulo: Cultura Acadêmica, 2014. p. 13-21.

CECCIM, R. B.; FEUERWERKER, L. C. M. Mudança na graduação das profissóes de saúde sob o eixo da integralidade. Cadernos de Saúde Pública, Rio de Janeiro, v. 20 , n. 5, p. 1400-1410, 2004.

CORÁCIO, F. C. C. et al. A experiência de uma instituição pública na formação do profissional de saúde para atuação em atenção primária. Ciência \& Saúde Coletiva, Rio de Janeiro, v. 19, n. 7, p. 2133-2142, 2014

DONNELLY, C. A. et al. The emerging role of occupational therapy in primary care. Canadian Journal of $O c$ cupational Therapy, Toronto, v. 81, n. 1, p. 51-61, 2014.

FREIRE, P. Extensão ou Comunicação? Rio de Janeiro: Paz e Terra, 1983.

LINS, S. R. A.; MATSUKURA, T. S. A formação graduada do terapeuta ocupacional no campo da saúde mental: a perspectiva de discentes e egressos. Cadernos de Terapia Ocupacional da UFSCar, São Carlos, v. 23, n. 4, p. 689-699, 2015a.

LINS, S. R. A.; MATSUKURA, T. S. Desafios e perspectivas da formação do terapeuta ocupacional no campo da saúde mental. Revista de Terapia Ocupacional da Universidade de São Paulo, São Paulo, v. 26, n. 3, p. $317-$ 325, 2015b.

LOPES, R. E. et al. XI Encontro Nacional de Docentes de Terapia Ocupacional: refletindo sobre os processos de formação acadêmica e profissional. Revista de Terapia Ocupacional da Universidade de São Paulo, São Paulo, v. 19, n. 3, p. 159-166, 2008

LOPES, R. E.; PAN, L. C. O ensino de terapia ocupacional social nas universidades públicas do Estado de São Paulo. Revista de Terapia Ocupacional da Universidade de São Paulo, São Paulo, v. 24, n. 2, p. 103-111, 2013.

MUIR, S. Health Policy Perspectives - Occupational therapy in primary health care: We should be there. American Journal Occupational Therapy, Rockville, v. 66, n. 5, p. 506-510, 2012. 
OLIVEIRA, G. N.; FURLAN, P. G. Co-Produção de Projetos Coletivos e Diferentes "Olhares" sobre o Território. In: CAMPOS, G. W. S. C.; GUERRERO, A. V. P. (Org.). Manual de Práticas de atenção básica: saúde ampliada e compartilhada. São Paulo: Aderaldo \& Rothschild Editores LTDA, 2008. p. 247-272.

OLIVER, F. C. et al. Formação do terapeuta ocupacional para o trabalho na Atenção Primária à Saúde (APS): contribuiçóes para o debate. Cadernos de Terapia Ocupacional da UFSCar, Sáo Carlos, v. 20, n. 3, p. 327-340, 2012.

OLIVER, F. C.; AOKI, M.; CALDEIRA, V. A. A formação do terapeuta ocupacional: contribuições da atenção básica em saúde. In: CONGRESSO PAULISTA DE SAÚDE PÚBLICA, 13., 2013, São Paulo. Anais... São Paulo: CPSP, 2013. p. 398-398.

PAIM, J. S.; TEIXEIRA, C. F. Configuração institucional e gestão do Sistema Único de Saúde: problemas e desafios. Ciência \& Saúde Coletiva, Rio de Janeiro, v. 12, p. 1819-1829, 2007. Suplemento.

PALM, R. C. M. Catálogo latinoamericano de asociaciones, carreras y postgrados de Terapia Ocupacional. Curitiba: CLATO, 2012.

PAN, L. C. Politicas de Ensino Superior, Graduação em Terapia Ocupacional e o Ensino de Terapia Ocupacional Social no Brasil. 2014. 224 f. Dissertação (Mestrado em Terapia Ocupacional) - Universidade Federal de São Carlos, São Carlos, 2014.

PIMENTEL, A. M.; OLIVER, F. C.; UCHÔAFIGUEIREDO, L. Formação do Terapeuta Ocupacional para o Trabalho na Atenção Primária em Saúde (APS). In: SEMINÁRIO DE TERAPIA OCUPACIONAL NA APS, 1., 2011, São Paulo. Anais... São Paulo: ATOESP: 2011. p. 1-4.
ROCHA, E. F.; PAIVA, L. F. A.; OLIVEIRA, R. H. Terapia ocupacional na Atenção Primária à Saúde: atribuições, açôes e tecnologias. Cadernos de Terapia Ocupacional da UFSCar, São Carlos, v. 20, n. 3, p. 351-361, 2012.

ROCHA, E. F.; SOUZA, C. C. B. X. Terapia Ocupacional em reabilitação na Atenção Primária à Saúde: possibilidades e desafios. Revista de Terapia Ocupacional da Universidade de São Paulo, São Paulo, v. 22, n. 1, p. 36-44, 2011

SALLES, M. M.; MATSUKURA, T. S. Estudo de revisão sistemática sobre o uso do conceito de cotidiano no campo da terapia ocupacional no Brasil. Cadernos de Terapia Ocupacional da UFSCar, São Carlos, v. 21, n. 2, p. 265-273, 2013.

SAMPIERI, R. H.; COLLADO, C. F.; LUCIO, P. B. Metodologia de Pesquisa. São Paulo: McGraw-Hill, 2013.

SILVA, R. A. S.; MENTA, S. A. Abordagem de terapeutas ocupacionais em Núcleos de Apoio à Saúde da Família (NASF) no estado de Alagoas. Cadernos de Terapia Ocupacional da UFSCar, São Carlos, v. 22, n. 2, p. 243-250, 2014.

SOARES, L. B. T. Terapia Ocupacional: lógica do capital ou do trabalho? São Paulo: Editora Hucitec, 1991.

SOUZA, F. R. Terapia ocupacional no apoio à equipe de saúde da família: como superar os desafios iniciais na implantação das açóes? Revista Baiana de Terapia Ocupacional, Salvador, v. 1, n. 1, p. 42-56, 2012.

STARFIELD, D. B. Atenção Primária: equilíbrio entre necessidades de saúde, serviços e tecnologias. Brasília: UNESCO/Ministério da Saúde, 2002.

WOOD, R.; FORTUNE, T.; MCKINSTRY, C. Perspectives of occupational therapists working in primary health promotion. Australian Occupational Therapy Journal, Melbourne, v. 60, n. 3, p. 161-170, 2013.

\section{Contribuições dos Autores}

Rodrigo Alves dos Santos Silva e Fátima Corrêa Oliver participaram igualmente de todas as etapas de elaboração do artigo. Ambos autores aprovaram a versão final do texto.

\section{Financiamento}

CAPES.

\section{Notas}

${ }^{1}$ Este estudo está vinculado à Pesquisa de Mestrado de Rodrigo Alves dos Santos Silva, que teve como título: $A$ Formação Graduada de Terapeutas Ocupacionais para o Cuidado na APS no Estado de São Paulo, realizada junto ao Programa de Pós-Graduação em Terapia Ocupacional da Universidade Federal de São Carlos.

${ }^{2}$ São mulheres todas as participantes docentes. A presença das mulheres na profissão é marcada historicamente e essas, como não poderia ser diferente, apresentam-se como maioria no exercício da prática de formação de terapeutas ocupacionais. 